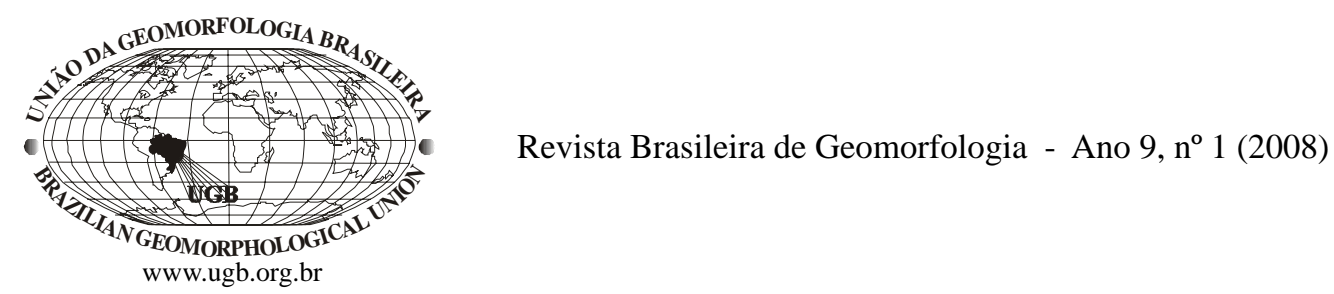

\title{
ANÁLISE DA FRAGILIDADE E VULNERABILIDADE NATURAL DOS TERRENOS AOS PROCESSOS EROSIVOS COMO BASE PARA O ORDENAMENTO TERRITORIAL: O CASO DAS BACIAS DO CÓRREGO CARIOCA, CÓRREGO DO BAÇÃO E RIBEIRÃO CARIOCA NA REGIÃO DO ALTO RIO DAS VELHAS-MG.
}

\author{
Clibson Alves dos Santos \\ Geógrafo/UNILESTE-Centro Universitário do Leste de MG. \\ E-mail: clibsonsantos@yahoo.com.br
}

End. Correspondência: Av. Luiz Ramirez, 255 Apto. 103 Cond. Pq. Recanto, Timóteo-MG, CEP: 35182-400. Telefone: (31) 92997549

Frederico Garcia Sobreira

Depart. de Geologia/UFOP-Universidade Federal de Ouro Preto E-mail: sobreira@degeo.ufop.br. Campus Morro do Cruzeiro s/n.

\begin{abstract}
Resumo
As bacias do Córrego Carioca, do Córrego do Bação e do Ribeirão do Carioca fazem parte da bacia do rio Itabirito, tributário no alto rio das Velhas, afluente do Rio São Francisco. Essa região é marcada por intensos processos erosivos, decorrentes do uso inadequado dos solos. Sendo evidenciados diversos conflitos de uso dos terrenos e recursos hídricos, devido ao desenvolvimento da atividade minerária, das atividades industriais, das práticas agropastoris, da crescente ocupação urbana e da expansão imobiliária por condomínios residenciais de classe alta. Nesse trabalho, analisou-se a susceptibilidade natural dos terrenos aos processos erosivos, tendo como base as unidades geomorfológicas definidas por Santos et al. (2006) e os métodos propostos por Crepani et al. (1996; 2001) e Ross (1992; 1994; 2000), visando contribuir no processo de planejamento ambiental e ordenamento territorial dessa região. Os resultados hierarquizam a área segundo o grau de fragilidade e vulnerabilidade aos processos erosivos, que associadas às análises realizadas no presente estudo, constituem-se em ferramentas orientativas no processo de ordenamento territorial das bacias hidrográficas estudadas.
\end{abstract}

Palavras-chave: processos erosivos, unidades geomorfológicas, ordenamento territorial.

\begin{abstract}
This paper analyzed of the fragility to erosion process of the watershed of the streams Carioca, Bação and Ribeirão Carioca, tributary of the Das Velhas basin. This area of the agriculture, farming, mining, of new land parceling, which due to the emergencial characteristics has been done without proper land use planning. Beyond, serious erosion process. Thus, was analyzed of the natural fragility of the landforms to the erosion process, through and the methods proposed at Ross (1992; 1994; 2000) and Crepani et. al. (1996, 2001). In the Ross (op. cit) methods the results show two groups main areas fragility to erosion, one group of the instability (60\% of the area) another stable, to share in the eight class of the fragility. The method of Crepani (op. cit) resulted in three groups of vulnerability, (high vulnerability - $28 \%$ of the area, middle vulnerability - 55\% of the area and low vulnerability $-17 \%$ of the area). The results they classify the area according to degree of fragility and vulnerability to the erosive processs, that associates to the analyses carried through in the present study is very important of the environmental management, prevention and/ or recovery of the erosion process, of the territorial zoning and of land use planed of the basins studied.
\end{abstract}

Keywords: deep gullies, geomorphological units, territorial zoning. 


\section{Introdução}

As bacias do Córrego Carioca, do Córrego do Bação e do Ribeirão do Carioca inserem-se nos limites do município de Itabirito, situado a $60 \mathrm{~km}$ a sudeste de Belo Horizonte (MG). Essas bacias correspondem a 22,3\% $\left(117,2 \mathrm{~km}^{2}\right)$ da bacia do rio Itabirito, tributário do alto rio das Velhas, afluente da cabeceira do Rio São Francisco (Figura 1).

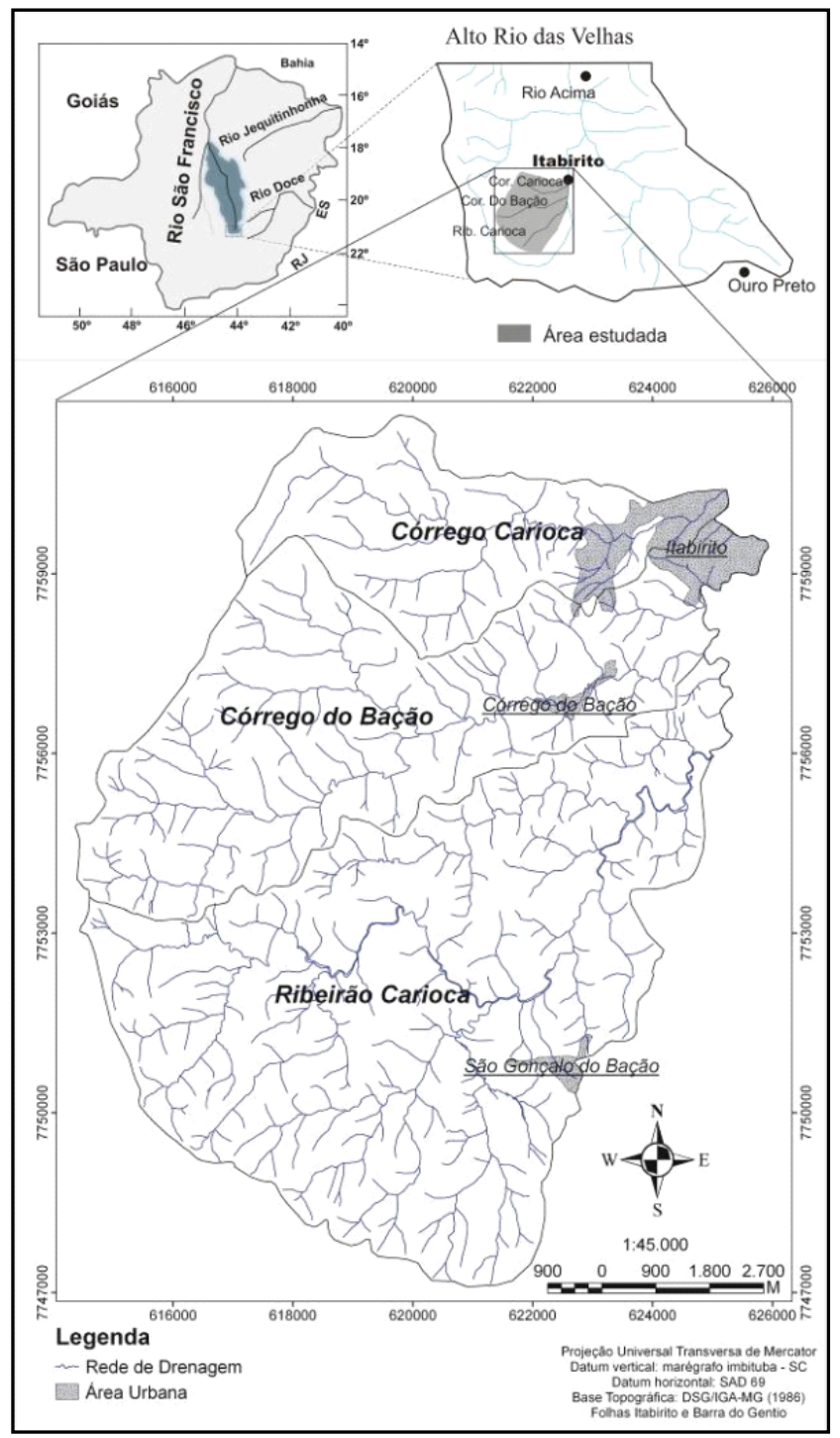

Figura 1 - Bacias hidrográficas estudadas no contexto da bacia do Rio das Velhas.

O Alto Rio das Velhas está inserido no contexto geológico do Quadrilátero Ferrífero (Figura 2), que segundo o Plano Diretor de Recursos Hídricos da Bacia do Rio das Velhas é uma das principais regiões de conflito de uso dos terrenos e recursos hídricos, devido ao desenvolvimento da atividade minerária, às atividades indus- triais, às práticas agropastoris, à ocupação urbana e expansão imobiliária por condomínios residenciais (Camargos, 2005).

O presente trabalho visa contribuir no planejamento ambiental e ordenamento territorial dessa região através da análise da susceptibilidade natural dos terrenos aos processos erosivos, tendo como base as unidades geomorfológicas definidas por Santos et al. (2006) e os métodos propostos por Crepani et al. (1996; 2001) e Ross (1992; 1994; 2000). Os conhecimentos geomorfológicos são fundamentais nesse processo, podendo subsidiar o entendimento de fenômenos como processos erosivos, inundações, instabilidade de terrenos e movimentos de massa, além de auxiliar na identificação das potencialidades e fragilidades naturais dos terrenos frente aos diversos tipos de uso e apropriação dos solos. Além do uso conflituoso dos recursos naturais e de ser marcada por ravinas e voçorocas (Tabela 2), as bacias estudadas são utilizadas pelo SAAE - Serviço Autônomo de Água e Esgoto de Itabirito, para o abastecimento da sede municipal e dos distritos da região.

\section{Meio Físico}

\section{Geologia}

Na área estudada, o Quadrilátero Ferrífero (Figura 2), é representado pelo Supergrupo (Sg) Minas formado por quartzitos, filitos e Itabiritos, pelos xistos do Supergrupo (Sg) Rio das Velhas e pelos granito-gnaisses do Complexo do Bação.

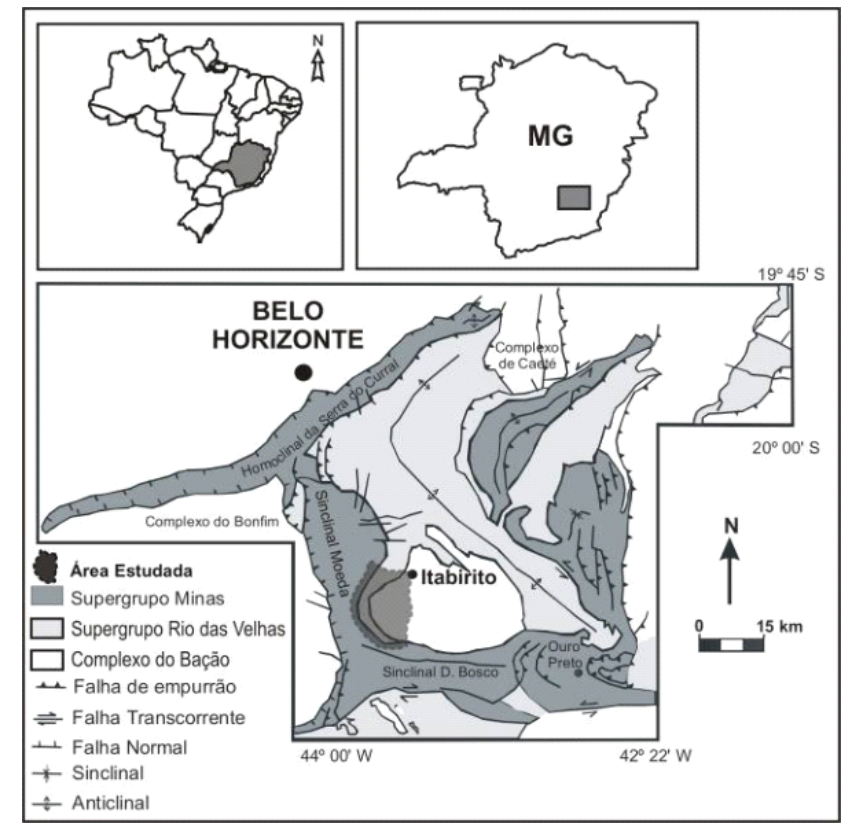

Figura 2 - Localização da área estudada no contexto da província geológica do Quadrilátero Ferrífero. 


\section{Solos}

Os solos apresentam uma estreita relação com a geologia e a geomorfologia local. Nas nascentes sobre relevo serrano, constituído de itabiritos, filitos e quartzitos do Sg. Minas, são observados Afloramento de Rochas mais Neossolos Litólicos (AR4) (Brandt Meio Ambiente, 2003). Os Cambissolos Háplico (Cxa) estão sobre relevo ondulado, formados por xistos (Sg. Rio das Velhas) e nos granito-gnaisses (Complexo do Bação). Os Latossolos Vermelho-amarelo (LVAd) basicamente são encontrados no relevo suavemente ondulado do Complexo do Bação (Brandt Meio Ambiente, 2003; IGA, 1996) e os Neossolos Flúvicos (RV) nas planícies e terraços fluviais.

\section{Cobertura Vegetal}

As bacias do córrego do Bação e do córrego Carioca estão mais preservadas, predominando a mata nativa (floresta estacional semidecidual), áreas reflorestadas e pequenas pastagens (Santos et al. 2003). A bacia do ribeirão Carioca é a que apresenta maior degradação ambiental, sendo marcada por processos erosivos (Tabela 2). A cobertura vegetal predominante é de campo cerrado e extensas áreas de pastagens.

\section{Unidades Geomorfológicas}

A base geomorfológica utilizada neste trabalho segue a proposta de Santos et al. (2006), que divide a área em sete unidades, sendo elas: Serra das Serrinhas, Alto da Carioca, Serra do Bação, Serra do Saboeiro, Depressão do Bação, Foz do Bação e Planícies do Bação (Figura 3), segundo as características morfológicas (formas de relevo e tipos de vertentes) e morfométricas (amplitude das formas, hipsometria e declividade) do relevo.

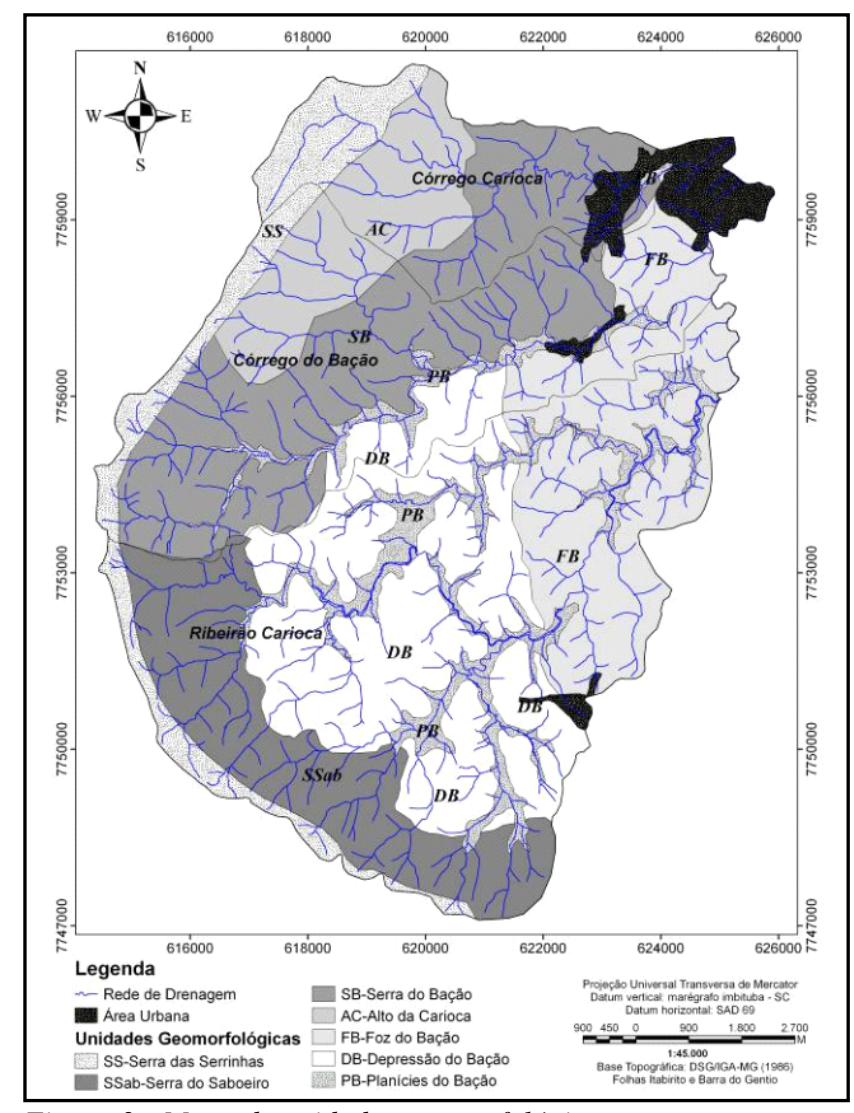

Figura 3 - Mapa de unidades geomorfológicas.

As tabelas 1 e 2 mostram ainda as características litológicas, pedológicas, uso e ocupação dos terrenos e a distribuição das ravinas e voçorocas nas unidades, segundo os estudos realizados por Santos et al. (2004) e Costa e Sobreira (2001).

\begin{tabular}{|c|c|c|c|c|c|c|c|c|c|}
\hline \multirow[b]{3}{*}{$\begin{array}{l}\text { Unidades } \\
\text { Geomorf. }\end{array}$} & \multirow{3}{*}{$\begin{array}{c}\text { Área } \\
\%\end{array}$} & \multicolumn{5}{|c|}{ Relevo } & \multirow[b]{3}{*}{ Litologia } & \multirow[b]{3}{*}{ Solos } & \multirow{3}{*}{$\begin{array}{l}\text { Cobertura } \\
\text { vegetal/Uso } \\
\text { do Solo }\end{array}$} \\
\hline & & \multicolumn{2}{|c|}{ Morfologia } & \multicolumn{3}{|c|}{ Morfometria } & & & \\
\hline & & Relevo & Vertente & $\begin{array}{c}\text { Amplitude } \\
\text { Topo/Base } \\
\text { (metros) }\end{array}$ & $\begin{array}{c}\text { Altimetria } \\
\text { (metros) }\end{array}$ & $\begin{array}{c}\text { Declive } \\
\text { médio } \\
(\%)\end{array}$ & & & \\
\hline $\begin{array}{l}\text { SS-Serra } \\
\text { das } \\
\text { Serrinhas }\end{array}$ & 6,61 & $\begin{array}{c}\text { Cristas } \\
\text { escarpadas }\end{array}$ & Retilíneas & 100 & $\begin{array}{l}1200- \\
1586\end{array}$ & $<30$ & $\begin{array}{c}\text { Itabiritos, } \\
\text { Filitos, } \\
\text { quartzitos e } \\
\text { xistos }\end{array}$ & $\begin{array}{l}\mathrm{LVj} \\
\mathrm{AR} 4\end{array}$ & $\begin{array}{c}\text { Pastagens e } \\
\text { Campo } \\
\text { Limpo }\end{array}$ \\
\hline $\begin{array}{l}\text { SSab- } \\
\text { Serra do } \\
\text { Saboeiro }\end{array}$ & 9 & Morros & $\begin{array}{l}\text { Côncavo } \\
\text { Convexa }\end{array}$ & $150-300$ & $\begin{array}{l}1100- \\
1250\end{array}$ & 30 & Xistos & $\mathrm{CXa}$ & $\begin{array}{c}\text { Uso } \\
\text { Agropastoril }\end{array}$ \\
\hline $\begin{array}{l}\text { SB-Serra } \\
\text { do Bação }\end{array}$ & 20 & $\begin{array}{c}\text { Morros } \\
\text { alongados }\end{array}$ & $\begin{array}{l}\text { Côncavas } \\
\text { Retilíneas }\end{array}$ & $150-300$ & $\begin{array}{l}1000- \\
1250\end{array}$ & 30 & Xistos & $\mathrm{CXa}$ & $\begin{array}{c}\text { Cerrado, } \\
\text { Campo } \\
\text { Limpo e } \\
\text { Uso } \\
\text { Agropastanil }\end{array}$ \\
\hline $\begin{array}{c}\text { AC-Alto } \\
\text { da } \\
\text { Carioca }\end{array}$ & 8,13 & Morros & Retilíneas & 300 & $\begin{array}{l}1100- \\
1250\end{array}$ & $>30$ & Xistos & $\mathrm{CXa}$ & Mata Nativa \\
\hline $\begin{array}{c}\text { FB-Foz } \\
\text { do Bação }\end{array}$ & 18 & $\begin{array}{l}\text { Monros e } \\
\text { morrotes }\end{array}$ & $\begin{array}{l}\text { Côncavo } \\
\text { convexas }\end{array}$ & $100-150$ & $850-1000$ & $15-30$ & $\begin{array}{l}\text { Granito- } \\
\text { gnaisses }\end{array}$ & $\mathrm{CXa}$ & $\begin{array}{l}\text { Mata Nativa } \\
\text { e Cerrados }\end{array}$ \\
\hline $\begin{array}{c}\text { DB- } \\
\text { Depressão } \\
\text { do Bação }\end{array}$ & 23 & $\begin{array}{c}\text { Monros e } \\
\text { colinas }\end{array}$ & $\begin{array}{l}\text { Côncavas } \\
\text { Retilineas }\end{array}$ & 100 & $\begin{array}{l}1000- \\
1200\end{array}$ & 15 & $\begin{array}{l}\text { Granito- } \\
\text { gnaisses }\end{array}$ & LVAd & $\begin{array}{c}\text { Uso } \\
\text { Agropastori } \\
\text { e Campo } \\
\text { Limpo }\end{array}$ \\
\hline $\begin{array}{c}\text { PB- } \\
\text { Planícies } \\
\text { do Bação }\end{array}$ & 15,3 & Planícies & Retilíneas & 30 & $850-1200$ & $<10$ & $\begin{array}{l}\text { Sedimentos } \\
\text { recentes }\end{array}$ & RV & Pastagens \\
\hline
\end{tabular}

Tabela 1 - Descrição das unidades geomorfológicas mapeadas na área de estudo (modificado de Santos et al.,2006). 
Tabela 2 - Distribuição das ravinas e voçoroca nas Unidades geomorfológicas (modificado de Santos et al. ,2004).

\begin{tabular}{|l|c|c|c|c|}
\hline \multirow{2}{*}{$\begin{array}{c}\text { Unidades } \\
\text { geomorfológicas }\end{array}$} & \multicolumn{4}{|c|}{ Processos Erosivos Acelerados } \\
\cline { 2 - 5 } & Ativo & Estab & Outros & Total \\
\hline Serra Serrinhas & 2 & 1 & - & 3 \\
\hline Alto da Carioca & - & 9 & - & 9 \\
\hline Serra do Bação & - & 2 & 1 & 3 \\
\hline Serra do Saboeiro & 15 & 5 & 2 & 22 \\
\hline $\begin{array}{l}\text { Depressão do } \\
\text { Bação }\end{array}$ & 33 & 34 & 28 & 95 \\
\hline Alto do Bação & 4 & 10 & 1 & 15 \\
\hline $\begin{array}{l}\text { Planícies do } \\
\text { Bação }\end{array}$ & - & - & - & - \\
\hline \multicolumn{1}{|c|}{ Total } & 54 & 61 & 31 & 147 \\
\hline
\end{tabular}

\section{Metodologia}

Para a análise da susceptibilidade natural aos processos erosivos, utilizou-se as propostas metodológicas de Ross (1992; 1994) e Crepani (1996; 2001), que sugerem a avaliação dos terrenos segundo a análise integrada dos aspectos do meio físico, resultando em registros cartográficos que expressam a fragilidade natural dos terrenos aos processos erosivos ou a vulnerabilidade natural à perda de solo. Nesse contexto, os termos fragilidade e vulnerabilidade significam a predisposição natural dos terrenos em serem erodidos.

Inicialmente, foram elaborados os mapas temáticos básicos (geológico, geomorfológico, pedológicos e cobertura vegetal/uso do solo) na escala de 1:25.000. Para tanto, foram realizados levantamentos bibliográficos e cartográficos, complementados por detalhamentos em trabalhos de campo, conforme descrito em Santos (2007). A integração dos dados relacionados ao meio físico foi feita de forma automatizada utilizando os recursos do ArcToolBox, aplicativo do ArcGis 9.0, sendo utilizadas as ferramentas do Analyst Tools/Overlay/Union. A partir desse procedimento, foi possível a identificação das Fragilidades dos Ambientes Naturais (Ross, 1992; 1994, 2000) e a definição das Unidades Territoriais Básicas - UTB’s, que expressam a Vulnerabilidade Natural dos Terrenos (Crepani, 1996; 2001). Para a área estudada, as análises tiveram como base fundamental as unidades geomorfológicas descritas na Tabela 1 e Figura 3.

\section{Fragilidade dos Ambientes Naturais}

No modelo proposto por Ross (1992; 1994, 2000), a análise da fragilidade pode ser feita a partir dos aspectos relacionados ao relevo seguindo duas formas de abordagem: em trabalhos de escala média (1:50.000, 1:100.000, 1:250.000) utiliza-se os Índices de Dissecação dos Relevo, abordando os aspectos morfométricos, e nos estudos em escalas de maior detalhe $(1: 25.000,1: 10.000,1: 5.000)$ utilizase como base as Classes de Declividades dos terrenos.

No presente trabalho, as análises foram realizadas seguindo uma escala de abordagem de 1:50.000, porém, a base topográfica foi extraída de mapas na escala de 1:25.000, com curvas de nível de 10 em 10 metros, que proporcionaram uma análise mais detalhada dos aspectos geomorfológicos. Com isso, a identificação do grau de fragilidade relativo ao relevo e dos demais elementos do meio físico foi feita através da combinação de ambos os métodos, tendo como referência as características identificadas nas unidades geomorfológicas (Tabela 1), complementados pela caracterização do comportamento pluviométrico da região, descrito em Santos (2007).

A proposta metodológica atribui um índice de fragilidade que varia de 1 a 5 para cada componente do meio físico analisado, conforme o grau de fragilidade para aquele parâmetro, conforme descrito em Ross (2000; 1994; 1992). O índice 1 indica maior resistência a ocorrência de processos erosivos e o índice 5 o contrário. Por exemplo, as Planícies e Terraços Aluviais, recebem o índice 1, pois são pouco susceptíveis a ocorrência de processos erosivos. Em Morros íngremes com vertentes retilíneas, esse índice é 5, por apresentar alta susceptibilidade a erosão. Dessa forma, são analisadas Formas de Relevo, Tipos de Solos, Cobertura vegetal/Uso do Solo e a Pluviometria da área em estudo, sendo atribuído um índice de fragilidade para cada uma dessas características. Após a definição do índice de fragilidade de cada elemento do meio físico, de forma automatizada, é feito a combinação das informações (associação entre os índices), que resulta no Índice de Instabilidade Emergente ou Potencial, definindo a Classe de Fragilidade daquele ambiente. A tabela 5 exemplifica a Classe de Fragilidade Potencial Muito Fraca, com a combinação dos seguintes índices: 1.2.2.3, 1.3.2.3 e 1.5.2.3. O primeiro dígito corresponde ao relevo, o segundo ao tipo de solo, o terceiro a cobertura vegetal e o quarto a pluviometria.

\section{Análise da Vulnerabilidade Natural a Erosão}

Segundo Crepani et al. (1996; 2001) a análise da vulnerabilidade natural dos terrenos aos processos de erosão (laminar e/ou linear) é feita a partir da identificação das UTB’s - Unidades Territoriais Básicas. A delimitação das unidades é feita sobre a imagem de satélite, a partir da interpretação na imagem de padrões semelhantes, identificados pelas variações de cores, textura, formas, padrões de drenagem e relevo (Crepani et al., 2001). No presente trabalho, essas unidades foram associadas às unidades geomorfológicas (Figura 3 e Tabela 1), definidas seguindo parâmetros semelhantes aos acima citados, conforme descrito em Santos (2007). Nesse mapa de unidades foi feita a associação das demais informações temáticas da região (geologia, pedologia, cobertura vegetal/uso dos solos e pluviometria). Em cada parâmetro é atribuído um valor de fragilidade ou grau de vulnerabilidade que varia de 1 a 3 (Tabela 3 ). Os valores próximos de 1 sugerem a estabilidade e os valores próximos de 3 indicam as áreas que apresentam instabilidade. 
Análise da fragilidade e vulnerabilidade natural dos terrenos aos processos erosivos como base para o ordenamento...

Tabela 3 - Valores de vulnerabilidade dos atributos do meio físico identificados na área estudada, tendo como base nos índices propostos por Crepani et al. (2001).

\begin{tabular}{|c|c|c|c|c|c|c|c|}
\hline Litologia & GV & Solos & GV & Geomorfologia & GV & Cobertura Vegetal & GV \\
\hline Quartzitos & 1,0 & LVAd & 1,0 & Alto do Bação & 1,7 & Floresta Nativa & 1,3 \\
\hline Granitóides & 1,1 & $\mathrm{LVj}$ & 2,0 & Depressão do Bação & 2,3 & Reflorestamento & 1,7 \\
\hline Gnaisses & 1,3 & CXa & 2,5 & Serra do Saboeiro & 2,4 & Cerrados & 2,2 \\
\hline $\begin{array}{l}\text { Xistos, } \\
\text { Itabiritos }\end{array}$ & 2,0 & \multirow{3}{*}{$\begin{array}{l}\mathrm{AR} \\
\mathrm{RV}\end{array}$} & \multirow{3}{*}{3,0} & Alto da Carioca & 2,5 & \multirow{3}{*}{$\begin{array}{l}\text { Pastagens, Campo } \\
\text { Limpo e Ârea Urbana }\end{array}$} & \multirow{3}{*}{3,0} \\
\hline \multirow{2}{*}{ Filitos } & \multirow{2}{*}{2,1} & & & Serra do Bação & 2,7 & & \\
\hline & & & & Serra das Serrinhas e Planícies do Bação & 3,0 & & \\
\hline
\end{tabular}

Onde, GV é igual a Grau de Vulnerabilidade. Os critérios para atribuir os GV cada característica do meio físico são descritos no com maiores detalhes em Crepani et al. (2001).

Após a identificação dos valores individuais dos parâmetros é feita a soma e obtida uma média, resultando no índice final, que representa o grau de vulnerabilidade daquela porção do terreno. Devido a homogeneidade, os aspectos climáticos não foram utilizados para aquisição das médias.

\section{Resultados e Discussões}

\section{Fragilidade dos Ambientes Naturais}

Para todas as características analisadas na área de estudo foram atribuídos graus de fragilidade (1 a 5), que agrupados resultaram em oito graus de fragilidade dos terrenos, agrupados em duas classes (Figura 4), as Unidades Ecodinâmicas de Instabilidade Potencial, mais próximas do equilíbrio dinâmico, representadas por ambientes que apresentam vegetação nativa e pouca pressão antrópica e as Unidades Ecodinâmicas de Instabilidade Emergente, que são áreas alteradas por intervenções antrópicas.

\section{Unidades Ecodinâmicas de Instabilidade Potencial}

Perfazem aproximadamente 35 \% da área de estudo, sendo identificadas quatro classes de fragilidade potencial, sendo elas: muito fraca, média, forte e muito forte. Essas unidades estão associadas principalmente às formas de relevo mais onduladas e às porções de cerrado e de mata nativa. Segue abaixo a descrição de cada uma das unidades e a tabela 5 exemplifica as características e a combinação dos valores da classe de fragilidade potencial muito fraca identificada na área de estudo.

a) Instabilidade Potencial Muito Fraca - correspondem a uma pequena porção de terras próximas ou associadas às Planícies do Bação, perfazendo um total de 1,9 km² ou 1,7\% da área de estudo. Os índices obtidos seguem as associações: 1.2.2.3, 1.3.2.3 e 1.5.2.3 (Tabela 3).

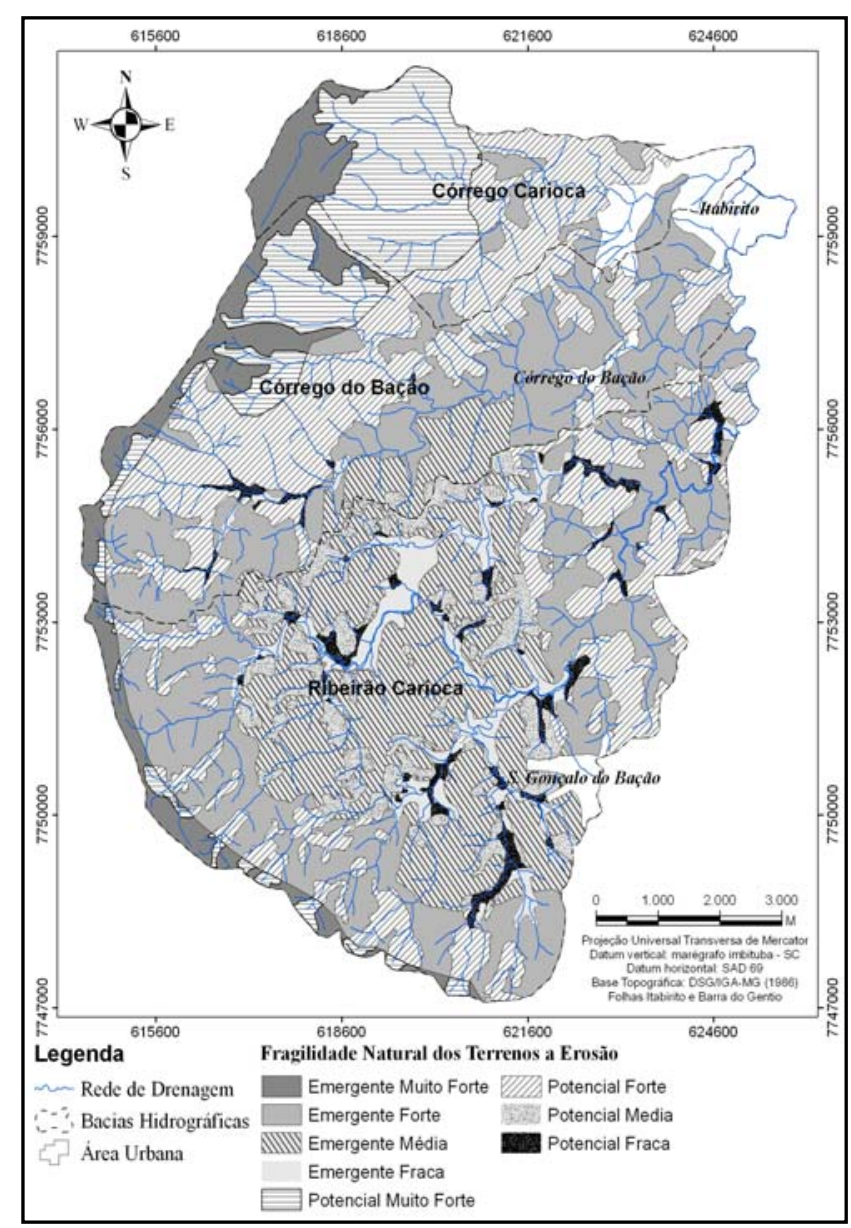

Figura 4 - Fragilidade natural dos terrenos frentes aos processos erosivos, segundo metodologia propostas por Ross (1992, 1994). 
b) Instabilidade Potencial Média - correspondem $5,5 \mathrm{~km}^{2}$ ou $5 \%$ da área estudada, inseridas principalmente na
Depressão do Bação e associadas a vegetação de Cerrado. Os índices obtidos seguem as associações: 3.5.2.3 e 3.2.2.3.

Tabela 3 - Descrição da classe de fragilidade Muito Fraca e do índice de instabilidade potencial dos elementos do meio físico.

\begin{tabular}{|c|c|c|c|c|c|c|}
\hline Unidades & $\begin{array}{l}\text { Classes de } \\
\text { Fragilidades }\end{array}$ & $\begin{array}{c}\text { Índices de } \\
\text { Instabilidade } \\
\text { Potencial }\end{array}$ & $\begin{array}{c}\text { Índice de } \\
\text { Dissecação do } \\
\text { Relevo/Classes } \\
\text { de Declives }\end{array}$ & Tipo de Solos & $\begin{array}{c}\text { Cobertura } \\
\text { Vegetal e } \\
\text { Uso do } \\
\text { terreno }\end{array}$ & Pluviometria \\
\hline \multirow{3}{*}{ 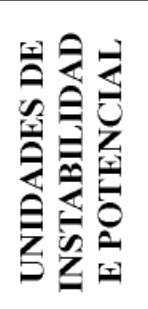 } & \multirow{3}{*}{ Muito Fraca } & 1.2 .2 .3 & \multirow{3}{*}{$\begin{array}{l}\text { Relevo pouco } \\
\text { dissecado e baixo } \\
\text { declive (menor } \\
\text { que } 6 \% \text { ). As } \\
\text { planícies e os } \\
\text { terraços. (1) }\end{array}$} & $\begin{array}{l}\text { Latossolo Vermelho } \\
\text { amarelo distrófico (2). }\end{array}$ & $\begin{array}{l}\text { Cerrados } \\
\text { (2) }\end{array}$ & \multirow{3}{*}{$\begin{array}{l}\text { Distribuição } \\
\text { anual desigual, } \\
\text { com períodos } \\
\text { secos no inverno } \\
\text { e chuvoso no } \\
\text { verão. (3) }\end{array}$} \\
\hline & & 1.3.2.3 & & $\begin{array}{l}\text { Cambissolos Háplicos } \\
\text { (3) }\end{array}$ & $\begin{array}{l}\text { Floresta } \\
\text { Nativa (2) }\end{array}$ & \\
\hline & & 1.5.2.3 & & Neossolos Flúvicos (5) & $\begin{array}{l}\text { Cerrados } \\
\text { (2) }\end{array}$ & \\
\hline
\end{tabular}

c) Instabilidade Potencial Forte - correspondem 25,6 $\mathrm{km}^{2}$ ou 23,5 \% da área estudada, distribuídas principalmente nas unidades geomorfológicas da Serra do Saboeiro, Alto do Bação e porção com maiores declividade da Serra do Bação. Apresentando os seguintes índices: 4.5.2.3, 4.2.2.3 e 4.3.2.3.

d) Instabilidade Potencial Muito Forte - correspondem basicamente a unidade Alto do Bação e parte da Serra das Serrinhas, perfazendo um total de $9,5 \mathrm{~km}^{2}$ ou $8,7 \%$ da área estudada. Apresentando as seguintes combinações: 5.3.2.3 e 5.5.2.3.

\section{Unidades Ecodinâmicas de Instabilidade Emergente}

Essas unidades perfazem aproximadamente 60\% da área estudada, estando associadas principalmente às formas de relevo mais suaves e às porções cobertas por pastagens, campo limpo e apresentam intensa pressão antrópica. Segue abaixo a descrição de cada uma das unidades e a tabela 6 exemplifica as características e a combinação dos valores da classe de fragilidade emergente muito forte.

a) Instabilidade Emergente Fraca - correspondem basicamente as Planícies do Bação, perfazendo um total de 6,4 $\mathrm{km}^{2}$ ou 5,9 \% do total da área estudada. Apresentado as seguintes combinações: 1.2.3.3, 1.3.5.3, 1.3.3.3, 1.5.3.3 e 1.5.5.3.

b) Instabilidade Emergente Média - correspondem a Depressão do Bação, sobre as áreas utilizadas como pastagens ou com vegetação do tipo campo limpo, perfazendo um total de $16,9 \mathrm{~km}^{2}$ ou $15,5 \%$ do total da área estudada. Apresentado as seguintes combinações: 3.2.3.3, 3.2.5.3, 3.3.3.3 e 3.5.3.3.

c) Instabilidade Emergente Forte - correspondem 37,1 $\mathrm{km}^{2}$ ou $34 \%$ do total da área estudada, distribuídas pelas unidades geomorfológicas da Serra do Saboeiro, Alto Bação e nas porções mais planas da Serra do Bação. Apresentado as seguintes combinações: 4.2.3.3, 4.2.5.3, 4.3.3.3, 4.3.5.3, 4.5.3.3 e 4.5.5.3.

Tabela 4 - Descrição da classe de fragilidade Muito Forte e dos índices de instabilidade emergente dos elementos do meio físico.

\begin{tabular}{|c|c|c|c|c|c|c|}
\hline Unidades & $\begin{array}{l}\text { Classes de } \\
\text { Fragilidades }\end{array}$ & $\begin{array}{c}\text { Índices de } \\
\text { Instabilidade } \\
\text { Emergente }\end{array}$ & $\begin{array}{c}\text { Índice de Dissecação } \\
\text { do Relevo/Classes de } \\
\text { Declives }\end{array}$ & Tipo de Solos & $\begin{array}{l}\text { Cobertura } \\
\text { Vegetal e Uso } \\
\text { do terreno }\end{array}$ & Pluviometria \\
\hline \multirow{3}{*}{ 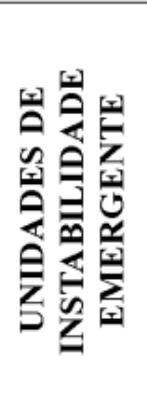 } & \multirow{3}{*}{ Muito Forte } & 5.2 .3 .3 & \multirow{3}{*}{$\begin{array}{l}\text { Relevo muito } \\
\text { dissecado com } \\
\text { declives acima de } \\
30 \% \text {. Morros com } \\
\text { vertentes retilíneas. } \\
\text { (5) }\end{array}$} & $\begin{array}{l}\text { Latossolo } \\
\text { Vermelho } \\
\text { amarelo } \\
\text { distrófico (2). }\end{array}$ & \multirow{3}{*}{$\begin{array}{l}\text { Pastagens, } \\
\text { Reflorestamento, } \\
\text { Campo Limpo } \\
\text { (3) }\end{array}$} & \multirow{3}{*}{$\begin{array}{l}\text { Distribuição } \\
\text { anual } \\
\text { desigual, com } \\
\text { períodos secos } \\
\text { no inverno e } \\
\text { chuvoso no } \\
\text { verão. (3) }\end{array}$} \\
\hline & & 5.3 .3 .3 & & $\begin{array}{l}\text { Cambissolos } \\
\text { Háplicos (3) }\end{array}$ & & \\
\hline & & 5.5 .3 .3 & & $\begin{array}{l}\text { Neossolos } \\
\text { Flúvicos (5). }\end{array}$ & & \\
\hline
\end{tabular}


Análise da fragilidade e vulnerabilidade natural dos terrenos aos processos erosivos como base para o ordenamento...

d) Instabilidade Emergente Muito Forte - correspondem basicamente sobre a Serra das Serrinhas e parte da unidade Alto da Carioca, perfazendo $6,5 \mathrm{~km}^{2}$ ou $6 \%$ do total da área estudada. Apresentado as seguintes combinações: 5233, 5333 e 5533. (Tabela 4).

A figura 5 mostra as freqüências das classes de fragilidade potencial e emergente identificadas na área de estudo.

e) Instabilidade Emergente Muito Forte - correspondem basicamente sobre a Serra das Serrinhas e parte da unidade Alto da Carioca, perfazendo $6,5 \mathrm{~km}^{2}$ ou $6 \%$ do total da área estudada. Apresentado as seguintes combinações: 5.2.3.3, 5.3.3.3 e 5.5.3.3. (Tabela 4).

A unidade geomorfológica denominada como Depressão do Bação foi classificada como de fragilidade emergente média a fraca (Figura 4) e com porções de instabilidade potencial. Segundo a aplicação do método proposto por Ross (1994) boa parte dessa área corresponde a ambientes que não sofrem pressão antrópica. Porém, observa-se em campo um comportamento diferente, pois a maior concentração de feições erosivas em forma de ravinas e voçorocas encontra-se nessa área, além dos diversos pontos de extração ilegal de areia nas planícies e terraços dos córregos, que foram classificados como de fragilidade emergente fraca e potencial média e muito fraca.

A Serra das Serrinhas é a região que apresenta o maior grau de instabilidade emergente da área estudada, seguida das unidades Serra do Saboeiro e Alto Bação, que foram classificadas principalmente como de instabilidade emergente forte, devido às características do relevo, muito dissecado e com altas declividades.

Os procedimentos técnico operacionais propostos nessa metodologia, resultam numa Carta de Fragilidade Ambiental decorrente da correlação simples entre as variáveis relevo, solos, cobertura vegetal/uso do solo e pluviosidade, que mostra-se como uma boa ferramenta orientativa nos planos de planejamento ambiental e ordenamento territorial, pois os graus de fragilidade identificados na área de estudo são muito próximos dos comportamentos observados em trabalhos de campo e outras análises realizados no presente trabalho.

\section{Análise da Vulnerabilidade Natural a Erosão}

Para a área estudada os resultados foram agrupados em três classes de vulnerabilidade, variando de baixa, média e forte (Figura 6). As classes de vulnerabilidade natural aos processos erosivos são assim descritas:

a) Vulnerabilidade Baixa - correspondem a $18 \mathrm{~km}^{2}$ ou $16,6 \%$ do total da área estudada, sendo observadas basicamente sobre áreas de latossolos vermelho-amarelo distróficos e cobertas por vegetação de cerrados e floresta nativa. Observa-se que essa unidade distribui-se sobre áreas de relevo suave (Depresão do Bação) a suavemente ondulado (Foz do Bação) (Figura 3).

Tabela 5 - Valores de vulnerabilidade dos atributos do meio físico identificados na área estudada, tendo como base nos índices propostos por Crepani et al. (2001). Onde, GVé igual a Grau de Vulnerabilidade.

\begin{tabular}{|c|c|c|c|c|c|c|c|}
\hline Litologia & GV & Solos & GV & Geomorfologia & GV & Cobertura Vegetal & GV \\
\hline Quartzitos & 1,0 & LVAd & 1,0 & Alto do Bação & 1,7 & Floresta Nativa & 1,3 \\
\hline Granitóides & 1,1 & $\mathrm{LVj}$ & 2,0 & Depressão do Bação & 2,3 & Reflorestamento & 1,7 \\
\hline Gnaisses & 1,3 & CXa & 2,5 & Serra do Saboeiro & 2,4 & Cerrados & 2,2 \\
\hline $\begin{array}{l}\text { Xistos, } \\
\text { Itabiritos }\end{array}$ & 2,0 & \multirow{3}{*}{$\begin{array}{l}\text { AR } \\
\text { RV }\end{array}$} & \multirow{3}{*}{3,0} & Alto da Carioca & 2,5 & \multirow{3}{*}{$\begin{array}{l}\text { Pastagens, Campo } \\
\text { Limpo e Ârea Urbana }\end{array}$} & \multirow{3}{*}{3,0} \\
\hline \multirow{2}{*}{ Filitos } & \multirow{2}{*}{2,1} & & & Serra do Bação & 2,7 & & \\
\hline & & & & Serra das Serrinhas e Planícies do Bação & 3,0 & & \\
\hline
\end{tabular}




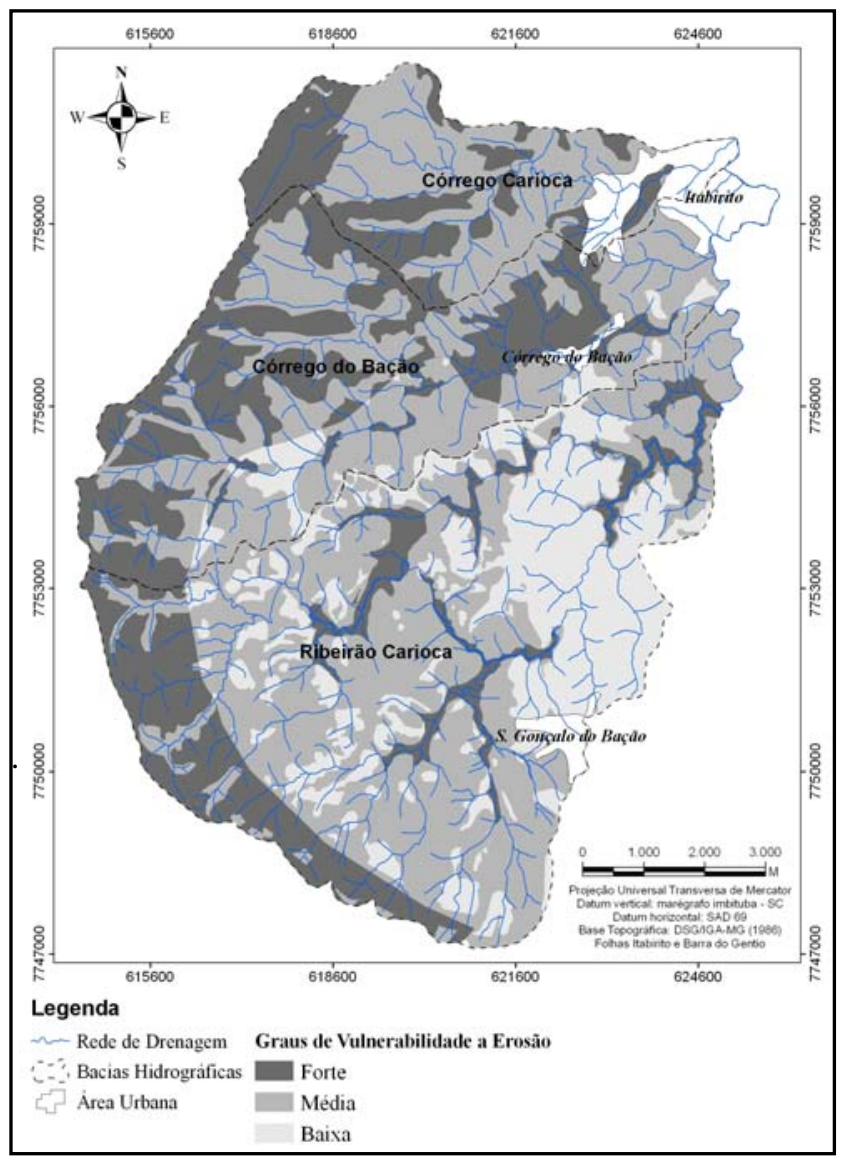

Figura 6 - Vulnerabilidade natural dos terrenos frentes aos processos erosivos, segundo metodologia proposta por Crepani et al. (2001).

b) Vulnerabilidade Média - distribui-se por praticamente toda a área estudada, correspondendo a $60 \mathrm{~km}^{2}$ ou $55 \%$ do total da área. Esse comportamento indica que em algumas regiões , principalmente sobre a Depressão do Bação a cobertura vegetal/uso do solo foi determinante, pois distribuise basicamente sobre pastagens.

c) Vulnerabilidade Forte - correspondem a $31 \mathrm{~km}^{2}$ ou 28,5\% do total da área estudada, sendo observadas basicamente sobre as áreas cobertas por cambissolos e em pequenas porções nas planícies e terraços fluviais.

Como observado acima, a Vulnerabilidade Média (55\%) é predominante se estendendo por todas as unidades geomorfológicas mapeadas, porém, esses ambientes são distintos em termos de características geomorfológicas, pedológicas e geológicas. Esse comportamento pode ser entendido pelo fato da metodologia propor uma média entre as variáveis. Com isso, elementos mais vulneráveis são amenizados pelos mais resistentes aos agentes erosivos. Comportamento semelhante pode ser observado nas áreas de
Vulnerabilidade Forte, que representam 28,5\% do total da área estudada.

Nas análises da vulnerabilidade segundo essa proposta, nota-se que não ocorre um padrão de comportamento das classes, pois nenhum dos parâmetros analisados se destaca como um fator preponderante da identificação das áreas. No caso das bacias hidrográficas analisadas, unidades que apresentam um relevo dissecado de alta vulnerabilidade a erosão, são atenuadas pela variável geologia pouco frágil. O mesmo ocorre em áreas que apresentam solos pouco desenvolvidos com fragilidade alta, que são amenizados pelo tipo de vegetação, que apresenta boa proteção ao terreno.

Isso pode ser observado nas áreas de vulnerabilidade baixa, que em boa parte, estão sobre cambissolos (GV 2,5 vulnerabilidade forte), cobertos por floresta nativa ou cerrados (vulnerabilidade muito baixa e baixa), e sobre relevo dissecado (vulnerabilidade forte), porém resultam em áreas de vulnerabilidade baixa. A metodologia proposta por Crepani (op. cit) possibilita que variáveis muito susceptíveis aos agentes erosivos, sejam amenizadas quando correlacionadas por variáveis muito estáveis.

\section{Conclusão}

Comparando os resultados obtidos percebe-se que a proposta de Ross $(1994 ; 2000)$ foi a que melhor se ajustou a realidade observada na área de estudo. Porém, os resultados tanto de uma quanto de outra metodologia, devem ser analisados com ressalva, pois os produtos cartográficos resultantes dos modelos podem mostrar respostas diferentes da realidade campo. Esse comportamento é observado na classificação obtida na unidade geomorfológica denominada Depressão do Bação, que é classificada apenas como de fragilidade média, porém, apresenta grande concentração de processos erosivos acelarados (Tabela 2), que provocam uma série de impactos na área de estudo, conforme descrito em Santos (2007).

Conclui-se que a aplicação de modelos pode não representar a realidade de campo, porém, são ferramentas valiosas na diferenciação básica entre os ambientes analisados e permitem estabelecer certo grau de padronização, mas que não substituem as análises de campo para a avaliação dos problemas e características ambientais.

No geral, a hierarquização da área segundo o grau de fragilidade ou vulnerabilidade aos processos erosivos, associadas às análises realizadas no presente estudo, constitui-se em ferramentas orientativas na definição de planos de recuperação, planejamento e zoneamento ambiental das bacias hidrográficas estudadas, que estão inseridas numa região de grande importância social, econômica e ambiental da porção central do estado de Minas Gerais. 
Análise da fragilidade e vulnerabilidade natural dos terrenos aos processos erosivos como base para o ordenamento...

\section{Referências Bibliográficas}

BRANDT Meio Ambiente. Contribuição do IBRAM para o zoneamento ecológico-econômico e o planejamento ambiental de municípios integrantes da APA-SUL RMBH - Itabirito/ MG. Vol. 1, 230p. 2003.

Camargos, L. M. M. 2005. Plano diretor de recursos hídricos da bacia hidrográfica do rio das Velhas: resumo executivo dezembro 2004. Belo Horizonte : Instituto Mineiro de Gestão das Águas, Comitê da Bacia Hidrográfica do Rio das Velhas. 226p.

CETEC - Fundação Centro Tecnológico de Minas Gerais. Diagnóstico Ambiental do Estado de Minas Gerais. Série de publicações técnicas. Belo Horizonte - MG. 1983.

Costa, F. M. \& Sobreira, F. G. 2001. Estudo Preliminar das voçorocas da bacia do Rio Carioca, Quadrilátero Ferrífero, MG. VII Simp. Nac. de Controle de Erosão. Goiânia-GO, ABGE, CD Anais.

Crepani, E.; Medeiros, J.S.; Azevedo, L.G.; Duarte, V.; Hernandez, P.; Florenzano, T. "Curso de Sensoriamento Remoto Aplicado ao Zoneamento Ecológico-Econômico”. INPE, São José dos Campos, SP, 1996.

Crepani, E.; Medeiros, J.S.; Azevedo, L.G.; Duarte, V.; Hernandez, P.; Florenzano, T; Barbosa, C.. "Sensoriamento Remoto e Geoprocessamento Aplicados ao Zoneamento Ecológico-
Econômico e ao Ordenamento Territorial”. INPE, São José dos Campos, SP, 2001.

IGA - Instituto de Geociências Aplicadas de Minas Gerais. Diagnóstico das condições físico-ambientais e do potencial turístico do município de ItabiritoMG. 11-16 p. 1996.

Ross, J. L. S. Análise empírica da fragilidade dos ambientes naturais e antropizados. In Revista do Depto. De Geografia - FFLCH-USP. N 8, São Paulo. 1994.

Ross, J. L. S. Geomorfologia: ambiente e planejamento. 5ed. São Paulo: Ed. Contexto. 85p. 2000.

Santos, C. A., Sobreira, F. G. \& Mergarejo Neto, M. 2004. Condicionantes do meio físico nas formas erosivas das bacias do Ribeirão Carioca, Córrego do Bação e Córrego Carioca, no município de Itabirito, MG. In. $5^{\circ}$ Simpósio Bras. de Cartografia Geotécnica e Geoambiental - ABGE, São Carlos-SP. Anais.

Santos, C. A., Sobreira, F. G. \& Silva, S. P. 2006. Cartografia geomorfológica como subsídio ao ordenamento territorial das bacias do ribeirão Carioca, córrego do Bação e córrego Carioca, Itabirito, MG. $6^{\circ}$ Simpósio Nacional de Geomorfologia. GoiâniaGO. UGB. CD Anais.

Santos. C. A. Diagnóstico e análise geoambiental das bacias hidrográficas do ribeirão Carioca e dos córregos Carioca e do Bação afluentes do rio Itabirito-MG, como subsídio ao zoneamento ambiental. Departamento de Geologia/Universidade Federal de Ouro Preto-MG. Tese de Doutorado, 186. 2007. 